\title{
Linking Transformational Leadership to Employee Turnover: The Moderating Role of Alternative Job Opportunity
}

\author{
Albert Amankwaa ${ }^{1} \&$ Olivia Anku-Tsede ${ }^{1}$ \\ ${ }^{1}$ Department of Organisation and Human Resource Management, University of Ghana, Ghana \\ Correspondence: Albert Amankwaa, Reasearch Assistant, Department of Organisation and Human Resource \\ Management, University of Ghana, Ghana. E-mail: amankwaaalbert@gmail.com
}

Received: June 1, 2015

Accepted: June 16, 2015

Online Published: July 5, 2015

doi:10.5430/ijba.v6n4p19

URL: http://dx.doi.org/10.5430/ijba.v6n4p19

\begin{abstract}
Corporations all over the world strive for competitiveness in the quest to improving the performance of their businesses. The issue of holding on to firms' talented employees has thus become critical in contemporary business operations. People must therefore be managed in ways which seek to elicit favorable behavioural responses targeted at creating customer satisfaction and consequent business efficacy. It is however not uncommon to find talented employees leave their current jobs for others. This paper therefore examined the influence of transformational leadership behaviours on employee turnover intention with the moderating effect of alternative job opportunity. A cross-sectional, descriptive, correlational survey design was adopted for the paper, with a multi-stage sampling approach used in selecting three hundred and five (305) employees from banks in Ghana. Correlational and hierarchical regressional analytical procedures were used to test the hypotheses. Transformational leadership behaviours were found to be negatively related to employees' voluntary organisational turnover intention but the availability of alternative job opportunities did not moderate the transformational leadership-turnover intention nexus. Within the Ghanaian banking industry, leadership behaviours that focus more on the needs of subordinates as a critical part of task accomplishment is laud by employees and thus mitigate their intention to quit the organisation for other lucrative offers. It is thus incumbent on management to employ more of transformational leadership behaviours as an efficient tool to addressing the severe consequences of turnover in the Ghanaian banking industry.
\end{abstract}

Keywords: transformational leadership, turnover intention, alternative job opportunity, moderator, Ghana, banking industry

\section{Introduction}

Literature is replete on leadership and voluntary employee turnover intention, with studies in both private and public sectors by various writers (e.g. Long, Adjgbe, Nor \& Suleiman, 2012; Vance, 2006). Even though most of these studies substantially found transformational leadership to be a strong mitigate of turnover, there is still inconclusive and contrasting findings with respect to which style of leadership mitigate the effects of turnover. Whereas some of these studies suggest that employees' intention to quit their jobs may be dependent on transformational leadership, others indicate that transactional leadership behaviour will substantially reduce turnover intention. For instance, Bycio, Hackett and Allen (1995) opined that transformational leadership tends to be the crucial style of leadership in reducing and mitigating turnover intention rather than transactional leadership and laissez-fair leadership and Najm (2010) in Kuwait also found a negative relationship between transactional and employees' turnover intention.

Again, Dwomoh and Korankye (2012) contend that financial liberalization has brought so many competitors in the Ghanaian banking industry sector and therefore for banks in Ghana to remain competitive, there is the compelling need to retain their existing employees who have been trained very well and are offering services to the satisfaction of their customers and this position is emphasized by Amediku (2008) that the issue of turnover has severe cost implications for the industry. Despite these indications, not much is known about leadership styles and their influence on employee turnover within the Ghanaian banking industry. Also, a greater number of studies (e.g. Muchiri \& Cooksey, 2011; Kedsuda \& Ogunlana, 2008) on leadership were done outside the sub-region and generalizing these findings globally may be problematic. Some scholars (e.g. Hofstede, 1984) explained that leadership behaviour is culturally determined and thus differs from one culture to the other. For instance, in the view of Hofstede, national culture can produce statistically significant differences in leadership behaviours. In cultures 
such as the United States and Canada where people believe that they can dominate their environment, individuals and leaders alike take a proactive view of change. However, in countries such as Iran and Ghana where people see themselves as subject to their environment, leaders tend to take a passive approach towards change. This assertion is similarly observed by Long, Thean, Ismail, and Jusoh (2012) in an exploratory study of Academic Staff in a Malaysian College, where it was observed that no significant relationship existed between leadership and turnover intention as opposed to the numerous studies. These authors indicated however that such conclusion could be as a result of the industry, that is, the context of the study. Having indicated the significant variations that culture may exert on research findings, it is imperative that current studies test earlier leadership styles and turnover intention findings in different contexts and socio-cultural orientations in order to contribute to the in-depth understanding and generalization of these findings in a developing country context.

Interestingly, most studies (e.g. Najm, 2010; Kedsuda \& Ogunlana, 2008) establish a relationship between transformational leadership and turnover intention. However, there is arguably no evidence in literature to suggest whether this bivariate relationship is altered, negatively or positively, by availability of alternative jobs even though Onyishi, Ucho and Mkavga (2012) and Mobley (1982) contend that turnover tends to be high in healthy economies (i.e. countries with low unemployment rates). The moderating construct, alternative job opportunity, thus became relevant in this paper owing to the fact that the unemployment rate in Ghana (12.5\%) is high and it will be statistically and practically inaccurate to assume that employees' decision to stay on or quit their jobs is solely fueled by leadership behaviours. These issues make it necessary for some research efforts to be exerted on examining the moderating effect of alternative job opportunity on the relationship between transformational leadership and employee turnover intention in the Ghanaian banking industry.

\subsection{Objectives of the Study}

The study sought to examine the following specific objectives:

- Determine the influence of transformational leadership style on employee turnover.

- Examine the moderating role of alternative job opportunity on the transformational leadership-turnover relationship.

\subsection{Hypotheses}

Out of the review of literature, the following hypotheses were explored:

$\mathbf{H}_{1}$ : Employees' perception of transformational leadership will negatively influence their turnover intention.

$\mathbf{H}_{2}$ : The relationship between transformational leadership and turnover intention will be moderated by alternative job opportunity.

\section{Literature Review}

\subsection{Leadership}

The concept of leadership is critical to employees' work attitudes, which significantly influence organisational performance, effectiveness, and behavioural outcomes. The willingness and decision to remain in a particular organisation immensely contributes to a firm's workforce stability and organisational effectiveness. To reinforce this position, Kozak and Ukah (2008) asserts that leadership is a vital tool for management because when properly used, it may enhance good relationships among employees, affect the organisational climate positively, increase service performance and modify behavioural outcomes. Researchers over the years have produced a number of works that thrive on the field of leadership research (House, Wright \& Aditya, 1997, Hukpati, 2009; Shamir, House \& Arthur, 1993). Although leadership is a term that is most often garnished with adjectives such as effective, good, bad and poor, previous researches have unsuccessfully provided a conclusive definition of the term leadership (Leithwood, Jantzi, \& Steinbach, 1999). Burns (1978) therefore described leadership as one of the most observed but least understood phenomena on earth. Nevertheless, Bryman (1992) posited that regardless of the lack of a clear definition, majority of the definitions of leadership reflect some basic elements including "group" "influence" and "goal".

Consistent with this assertion, Schermerhorn (1999) defined leadership as a process used to motivate and to influence others to work hard in order to realize and support organisational goals. Burns (1978) in his publication, "Leadership", gave the following as definitions of leadership: Leaders induce followers to act for certain goals that represent the values and the motivations-the wants and needs, the aspirations and expectations-of both leaders and followers. The genius of leadership lies in the manner in which leaders elect to act on their own and followers' values and motivations. Bass (1990) observed leadership as a process of interaction among individuals and groups that include a structured or restructured situation, members' expectations and perceptions. According to Jong and 
Hartog (2007), leadership is a process to influence people in order to get desired results. Thus, leaders help to stimulate, motivate, encourage, and recognize their followers' behaviours in order to get key performance results (Gill, Flaschner, \& Shacha, 2006).

Leadership style is defined by Hersey and Blanchard (1993) as the pattern of behaviours that leaders display during their work with and through others. According to Miller, Walker and Drummond (2002), leaders should cultivate styles that enhance interactions between them and subordinates. These researchers went on to define leadership style as the pattern of interactions between leaders and subordinates. To them, leadership style should include controlling, directing, indeed all techniques and methods used by leaders to motivate subordinates to follow their instructions. Leadership behaviours within organisations may however vary in terms of types and forms. Research on leadership has recognized different leadership styles that leaders use in managing follower-behaviours. For instance, Lewin, Lippit, and White (1939) based on leaders' participation and activeness in employees' behaviour towards work and decision making, identified three leadership styles known as autocratic, democratic, and laissez faire. In the autocratic leadership behaviour, decisions are made by the leader without the consent of subordinates or other colleagues. Lewin et al. found in their experiments that this caused the greatest displeasure. However, they observed that autocratic behaviour is not bad in all circumstances as it was found most appropriate where: there is no need for input on the decision; the decision would not change as a result of input; and the motivation of people to carry out subsequent actions would not be affected whether they were or were not involved in the decision-making.

In the democratic leadership behaviour, the leader involves the people in the decision-making although the process for the final decision may vary from the leader having the final say to facilitating consensus in the group. According to Lewin et al., democratic decision-making is usually appreciated by the people, especially if they have been used to autocratic decisions with which they may have disagreed. They however observed that, democratic leadership behaviour may not be the panacea for all situations. It could be problematic when there are a wide range of opinions and there is no clear way of reaching an equitable final decision. Finally, the third leadership behaviour, Laissez-faire, that was identified by Lewin et al. minimizes the leader's involvement in decision-making. Laissez-faire works best when people are capable and motivated in making their own decisions; where there is no requirement for a central coordination.

For the purpose of this study, however, Bass and Avolio's (2004) full range leadership theory in an effort to capture a broad spectrum of leadership styles expected to have a bearing on employees' intention to stay with or quit the organisation was adopted. In this approach, leadership was conceptualized by the behavioural areas from laissez-faire style, through transactional leadership, which hinges on reward system and punishments, to transformational leadership, which is based on inspiration and behavioural charisma. Specifically, transformational leadership was employed because of its currency in management research and the efficacy demonstrated through previous research findings.

\subsubsection{The Concept of Transformational Leadership}

Transformational leadership theory was developed in the late 20th century. It was introduced by James McGregor; Burns (1979) in his analysis related to it as the political leadership. Burns characterized transformational leadership as one which occurs when one or more persons engage with others in such a way that leaders and followers raise one another to higher levels of motivation and morality. He defined transformational leadership as a process in which leaders and followers help to improve motivation and morale to a higher level (Komives \& Wagner, 2009). In 1985, Bass refined and expanded Burns' leadership theory. To Bass, a leader is one who motivates people to do more than they are originally expected to do. He further argued that the mentioned motivation could be achieved by raising the awareness level about the importance of outcomes and ways to reach them. From Bass' perspective, transformational leadership is premised on how the leader affects followers who intend to trust, admire, and respect the transformational leader. Transformational leadership focuses more on change, and inspires followers to commit to a shared vision and goals for a unit or an organisation, challenging them to be innovative problem solvers, and developing followers' leadership capacity via coaching, mentoring, and provision of both challenge and support (Bass \& Riggio, 2006).

Over the past 10 years, transformational leadership has become one of the most prevalent topics within the leadership literature. The theory according to Burns (1978) hinges on some assumptions: People will follow a person who inspires them; a person with vision and passion can achieve great things; and the way to get things done is by injecting enthusiasm and energy. Transformational leaders according to Bass (1990: p. 21), "broaden and elevate the interests of their employees, when they generate awareness and acceptance of the purposes and mission of the group, and when they stir their employees to look beyond their own self-interest for the good of the group". The author 
proposed that transformational leadership comprises inspirational leadership, consisting of charismatic behaviours such as role modeling and risk sharing, attributed charisma, and inspirational motivation, which includes clearly communicating high expectations concerning a vision. Bass and Avolio (2004) proposed that transformational leaders exhibit various types of behaviours. Extant literature (e.g. Bass 1985, 1990; Bass \& Avolio, 1985) indicates that there are four components of transformational leadership, that is, idealized influence, inspirational motivation, intellectual stimulation, and individualized consideration. Transformational leaders accomplish this by employing the four behavioural components synonymous with transformational leadership practices.

Similar to the study of Bass and Avolio (2004), this paper typically categorized and operationalized transformational leadership behaviour into four broad dimensions namely Idealized influence, Inspirational motivation, Intellectual stimulation and Individualized consideration. Although some scholars (e.g., Antonakis et al. 2003; Bass \& Avolio) advance evidence to suggest that these four dimensions are distinguishable, they are often highly correlated and, thus, combined to form a single overall measure of transformational leadership. Bass observed that transformational leadership is considered effective in any culture or condition because it does not specify any conditions under which it is irrelevant or ineffective.

\subsection{Employee Turnover}

The prevalence of employee turnover is global and no different in West Africa and other parts of the continent. For instance, report on private sector demand for youth labour in Ghana and Senegal from the Youth Employment Network confirmed that high personnel turnover rates remained a major concern in the banking sector and other financial services in Ghana (The Youth Employment Network, 2009). Also, a study conducted by Amediku (2008) on employment and labour cost in Ghanaian banking sector indicated that employee turnover has serious cost implications for the industry. Even though the term turnover intention has been accepted by some scholars (e.g. Arnold, 1999) as a proxy construct for measuring actual turnover, it is still imperious to differentiate between these two constructs to facilitate a better appreciation of the terms. According to Loquercio, Hammersly, and Emmemns (2006), staff turnover could be defined as the proportion of staff leaving in a given period but prior to the anticipated end of their contract of employment. Turnover could either be voluntary or involuntary. Voluntary turnover describes the amount of employee turnover that occurs due to the decision of employees to resign from their positions and voluntarily leave their employers. This is in contrast to involuntary turnover, which is turnover that occurs without the consent of the employee. Thus, whereas involuntary turnover may be due to long term sickness, death, travel, or employer-initiated termination, voluntary turnover focuses mainly on situations in which employees elect to tender in resignations for various reasons, rather than their appointment being terminated at the discretion of an employer.

As indicated by Vance (2006), employee turnover can never be underestimated giving the cost organisations incur as a result. Extant literature (e.g. Najm, 2010; Kahumuza \& Schlechter, 2008), however, suggests that employee turnover may be substantially reduced if leaders exhibit behaviours which reflect employees' expectations of quality leadership. Notwithstanding that significant numbers of these studies established a significant negative relationship between leadership styles and employee turnover; there is not much in the literature to suggest how the relationship may be altered, positively or negatively, by alternative job opportunity given the rate of unemployment $(12.5 \%)$ in Ghana. It is on this premise that this paper sought to investigate the moderating role of alternative job opportunity in the leadership-turnover nexus in the Ghanaian banking industry. Extant literature has indicated turnover intention as a major concern for organisations. For instance, Kumar, Ramendran, and Yacob (2012) contended that turnover causes organisations to lose sales due to the amounts involved in recruiting and selecting new employees not alienating the cost of training the new employees to acquire the requisite skills and expertise. This statement is not different from the assertions of several authors in the turnover literature (e.g. Vance, 2006; Chapman, 1993) and this indicates the critical implications that turnover has on organisations. Turnover has been viewed in the literature to have adverse effects on organisations.

For instance, Khatri, Budhwar, and Fern (1999) in Asian countries such as China, Hong Kong, Malaysia, Singapoore and Taiwan found that employee turnover is a phenomenon that bedevils human resource managers. Also Amediku (2008) indicated that employee turnover in the Ghanaian banking sector has a lot of cost implications for the industry. Although Staw (1980) observed that turnover may have positive consequences, such as reallocation of organisational resources, this paper focused on negative consequences of turnover. The three core negative effects that the study sought to discuss were the implication on the organisational cost as posited by Vance (2006) and Amediku (2008), among others. The next was how the quitting of talented employees could disrupt the operations of the business and finally the effect on the morale of employees towards work. When an employee leaves an organisation, it exerts pressure on the organisation to spend scarce resources-both time and money-to either replace the employee, or get 
others to cover the work. Organisations spend a significant portion of their budgets recruiting and training new employees; estimates for the losses range from a few thousands to more than two times the person's salary (Cascio, 2000; Hinkin \&Tracey, 2000). Organisations incur both direct and indirect expenses when replacing a worker. Ali (2009) emphasized that high turnover brings destruction to the organisation in the form of both direct and indirect cost.

According to John (2000), some of the replacement costs include the search of the external labour market for a potential substitute, selection between competing substitutes, induction of the chosen substitute, and formal and informal training of the substitute until he or she attains performance levels equivalent to the individual who quit. Furthermore, some of the costs may comprise the disruption of the organisation's daily operations and the emotional stress. At times it includes the work overload it causes those who remain, which perhaps is difficult to capture in monetary terms. Gustafson (2002) posited that turnover comprises such other costs as lost productivity, lost sales and management's time. The author estimated that the turnover cost of an hourly employee is between $\$ 3,000$ and $\$ 10,000$. There is loss of intellectual capital to the already incurred cost. This is because it is not only the human capital and relational capital that organisations lose when employees exit, but also their competitors perhaps are potential benefactors of these assets. Therefore, it is imperative to note that when turnover occurs it can actually have social and psychological effects and can also project an adverse image of the organisation internally and externally.

\subsubsection{Implications of Employee Turnover to Organisations}

Literature has shown that turnover affects organisational effectiveness and this has serious implications for the bottom line of businesses. The impact of turnover is however mostly expressed in financial terms. For instance, Vance (2006) opined that Caterpillar, a giant multi-national construction equipment manufacturer, saved about $\$ 9$ million in turnover costs alone at one of its European based plants. Similarly, Tziner and Birati (1996) in an extension of Cascio's categories of monetary costs indicated that an organisation incurs huge costs as a result of turnover.

Operational disruption occurs when there is high interdependence of work roles within the organisation. The loss of key employees, which is characterized as being highly interdependent and specialized, may influence the ability of remaining employees in fulfilling their tasks. In some organisations, higher turnover rate is found in lower hierarchy levels because replacing these positions is not that difficult for the organisation. According to Staw (1980: p. 256), "the higher the level of position to be filled the greater the potential for disruption".

Employees leave organisations with perceived reasons and these reasons arguably are strong sources of demoralization among other employees in the organisation. The argument is that if the perceived reasons of turnover are caused by individual factors, then, demoralization is less existent; however, if the perceived reasons are caused by organisational factors, such as leadership behaviours, then it is likely to result in demoralization. This assertion is in line with Staw's (1980: p. 257) position that, "If those who leave are members of a cohesive work group or possess high social status among the organisational membership, then turnover will likely lead to greater demoralization".

\subsection{Empirical Review of Transformational Leadership and Employee Turnover}

There is a growing body of literature focusing on the effects of transformational leadership on turnover intention. Transformational leadership has been reported in the leadership literature to be significantly related to turnover intention. For instance, Dupre and Day (2007) asserted that factors associated with supportive management of employees were negatively related to turnover intention through the mediating effect of job satisfaction. Similarly, Alexandrov, Babakus and Yavas (2007) argued that employees' perception of management concern for both employees and customers has a significant influence on turnover intention. Several researchers have supported this position of literature. Hamstra, Yperen, Wisse, and Sassenberg (2011), in a quantitative study on how a fit between leadership styles and followers' regulatory focus will mitigate followers' turnover intention, found that transformational leadership was negatively related to turnover intention for highly promotion-focused followers, but not for those low in promotion focus. Similarly, Pieterse-Landman (2012) in a non-experimental quantitative study examined the relationship between leadership and employee turnover intention. Using a data from a sample of 185 managers in local JSE-listed manufacturing companies in South Africa, the author found a significant negative relationship between transformational leadership and intention to quit. Consistent with these findings, a study by Hughes, Avey and Nixon (2010) on leadership and followers' quitting intention and job search behaviours reported that followers' perceptions of transformational leadership shared significant inverse relationships with their intention to quit. In other words, these scholars found that when followers perceive their leaders as behaving transformationally and thus report a higher-quality exchange relationship, their preparatory job search feelings and 
intention to quit are less salient. Furthermore, Long et al. (2012) in an exploratory study examined the relationship between leadership styles and employee turnover intention among academic staff in a community college in Malaysia. Despite the fact that the relationship was not significant as compared to the stance of extant literature, these authors found that transformational leadership was negatively related to turnover intention.

In line with the position of previous findings, Bycio et al. (1995) opined that transformational leadership tends to be the crucial leadership behaviour in reducing and mitigating turnover intention rather than transactional leadership and laissez-fair leadership. Najm (2010) in Kuwait also found a negative relationship between transformational leadership and employees' turnover intention. A study by Martin and Epitropaki (2001) revealed that transformational leadership was negatively related to turnover intention among employees for several commercial and profit-oriented based businesses. Again, Gul, Ahmad, Rehman, Shabir and Razzaq (2003) conducted a study to investigate the association between leadership styles, organisational commitment and turnover intention. Out of the one hundred and seventy (170) questionnaires distributed, one hundred and twenty one (121) questionnaires were returned indicating a response rate of $71.2 \%$. The findings of the study indicated that there was insignificant negative association between turnover intention and transactional and transformational leadership styles. Finally, Wells and Pearchey (2011) undertook a study to investigate the relationship between leadership behaviours (transformational and transactional), satisfaction with the leaders, and voluntary turnover intention on 200 participants from National Collegiate Athletic Association Division I softball and volleyball assistant coaches in the USA. The outcome of their study showed significant negative correlation between transformational leadership style and voluntary turnover intention as well as the relationship between transactional leadership behaviour and voluntary organisational turnover intention. Based on the foregoing review, it was conjectured that transformational leadership behaviour would have a significant inverse relationship with employees' turnover intention.

H1: Employees perception of managers' transformational leadership behaviours will mitigate their turnover intention.

\subsection{Alternative Job Opportunity as a Moderator}

Alternative job opportunity refers to the availability of alternative, attractive and attainable employment offers in the business environment. The interaction of supply and demand forces in the economy may be taken into consideration in measuring external opportunities. The availability is mainly about the number of opportunities outside the organisation; the attractiveness refers to the pay levels and any other 'motivators' and 'satisfiers' of such opportunities. Last but not least, attainability is defined by the possession of the skills required on the job (Mueller \& Price, 1990). That is, numerous higher paid jobs for which a worker is qualified should produce a greater turnover. The argument is that, an employee's perception of lack of alternative job should not be considered as a form of commitment but as an independent construct that predicts employee behaviours such as turnover or commitment. This position was later held by these same pioneering authors (Allen and Meyer, 2000) who no longer observed perceived alternative jobs as a dimension of commitment. Empirically research has determined that employees' perception of employment alternatives is a cause, $n$

\section{Methodology and Analyses}

In this paper, a cross-sectional, correlational survey design was employed as the strategy for examining the moderating effect of alternative job opportunity on the transformational leadership - employee turnover relationship. The target population of the paper comprised employees of all the branches of Commercial banks listed on the Ghana Club 100 (GC 100), 2011 edition. According to the ranking, there were fourteen (14) Commercial banks on the GC 100 list. The accessible population, however, was limited to employees in the fourteen (14) Commercial banks located in the Greater Accra region. The selection was based on the fact that approximately $90 \%$ of the Commercial banks in Ghana have their headquarters and their top-performing branches concentrated in the capital, Greater Accra. Out of the accessible population of about 2800 employees, a sample size of 350 was estimated using the mathematical equation developed by Miller and Brewer (2003). Questionnaire was used as the survey instrument for gathering responses. The instrument comprised biography of respondents, transformational leadership items, turnover items and alternative job opportunity items. The 19-item transformational leadership behaviour was measured by the items using Bass and Avolio's (2004) Multifactor Leadership Questionnaire (MLQ 5x Short). Also, employee turnover was measured using Jackofsky and Slocum's (1987) 4-item Turnover Intention Questionnaire [TIQ] and alternative job opportunity measured using the revised organisational commitment questionnaire by Meyer and Allen.

This paper employed a multi-stage probability sampling technique for the selection of the respondents. First, the proportional stratified sampling technique was used to categorize the number of branches into strata on the basis of 
branches ( 5 branches per bank). This ensures a proportional representation in the study. It is however worth mentioning that the study primarily focused on the employees within the banking industry and thus the unit of interest was not necessarily where (the banks) the respondents worked but the fact that they were employees of any of the commercial banks on the GC100 list. Therefore, in the subsequent stage, the simple random sampling technique was used to draw participants from the 70 branches (i.e. 350/14 $=25$ employees per bank). The researcher randomly selected 25 employees from the five branches of each bank. As a result, each individual in the selected branch had an equal and calculable chance of being selected during the sampling process and this enabled the researcher to generalize the findings beyond the sample distribution. Due to the sensitive nature of turnover, various Human Resource managers of the participating banks were assured that the names of their branches would be anonymous; employees were also assured that their details provided will be kept confidential.

\section{Results and Examination of Hypotheses}

\subsection{Relationship between Transformational Leadership and Turnover Intention}

Table 1. Correlation analysis for leadership, alternative job and turnover intention

\begin{tabular}{lll}
\hline Variable & $\mathbf{r}$ & $\boldsymbol{\Delta} \mathbf{R}^{2}$ \\
\hline Control Variables & & \\
Age & -.086 & \\
Gender & .539 & \\
Marital Status & -.061 & \\
Level of Education & -.088 & \\
Job Position & -.056 & $.006^{* *}$ \\
Tenure & -.107 & \\
\hline Predictor Variables & & \\
Transformational Leadership & $-.289^{* *}$ & $.130^{*}$ \\
Alternative Job Opportunity &
\end{tabular}

Note: $\mathrm{N}=305 ; *$ indicate $p<.05, * *$ indicate $p<.01$.

Hypothesis 1 predicted that employees' perception of transformational leadership behaviours of managers in the Ghanaian banking industry will be negatively related to their turnover intention in the industry. To test this, the Karl Pearson's Product Moment Correlation Coefficient and hierarchical regression analyses were employed. The results from Table 1 revealed that transformational leadership behaviours in the Ghanaian banking industry was negatively correlated to turnover intention $(\mathrm{r}=-.286, \mathrm{p}<.01)$. Further, results from the hierarchical regression in Table 2, when age, gender, marital status, and tenure were controlled, indicated that transformational leadership behaviours explain a significant amount of incremental variance in employees' turnover intention $(\beta=-.289 ; \Delta \mathrm{R}=.006 ; \mathrm{p}<.01)$. Thus, transformational leadership behaviours mitigate employees' turnover intention within the Ghanaian banking industry. Hence, hypothesis 1 was supported.

Table 2. Hierarchical moderated multiple regression analysis for transformational leadership and turnover intention

\begin{tabular}{llllll}
\hline Variable & $\boldsymbol{\beta}$ & $\mathbf{R}^{2}$ & $\mathbf{\Delta \mathbf { R } ^ { 2 }}$ & $\mathbf{F}$ & $\mathbf{\Delta}$ \\
\hline Step 1 & & & & & \\
\hline $\begin{array}{l}\text { Transformational leadership } \\
\text { Step 2 }\end{array}$ & $-.289^{* *}$ & .083 & $.083^{* *}$ & $27.600^{* *}$ & 27.600 \\
$\begin{array}{l}\text { Transformational leadership } \\
\text { (A) }\end{array}$ & $-.274^{* *}$ & .089 & .006 & $14.787^{* *}$ & 12.813 \\
$\begin{array}{l}\text { Alternative Job Opportunity } \\
\text { (B) }\end{array}$ & .077 & & & & \\
Step 3 & & & & & \\
$\begin{array}{l}\text { Transformational leadership } \\
\text { (A) }\end{array}$ & $-.274^{* *}$ & 0.089 & .000 & $9.827^{* *}$ & 4.960 \\
$\begin{array}{l}\text { Alternative Job Opportunity } \\
\text { (B) }\end{array}$ & .077 & & & & \\
Interaction (A) $\times(B)$ & -.004 & & & & \\
\hline $305 ; *$ indicate $p<.05, * *$ indicate $p<.01$. & & &
\end{tabular}

Note: $\mathrm{N}=305 ; *$ indicate $p<.05, * *$ indicate $p<.01$. 


\subsection{Alternative Job Opportunity as a Moderator}

Hypothesis 2, predicted that the transformational leadership-turnover relationship will be moderated by availability of alternative job opportunities in the Ghanaian banking industry. To test this, a three-step level moderated hierarchical regression was employed. As illustrated in Table 2, the results of the moderated hierarchical regression analysis revealed that the beta coefficients of transformational leadership and alternative job opportunity were -.274 and .077 respectively. Finally, the interaction term had a beta coefficient of -.004 but it did not explain a significant incremental variance in turnover intention $\left(\Delta \mathrm{R}^{2}=.000\right)$. Thus, the interaction as illustrated in Figure 1 depicts that alternative job opportunity did not moderate the relationship between transformational leadership and employee turnover intention. Hence, hypothesis 2 was not supported.

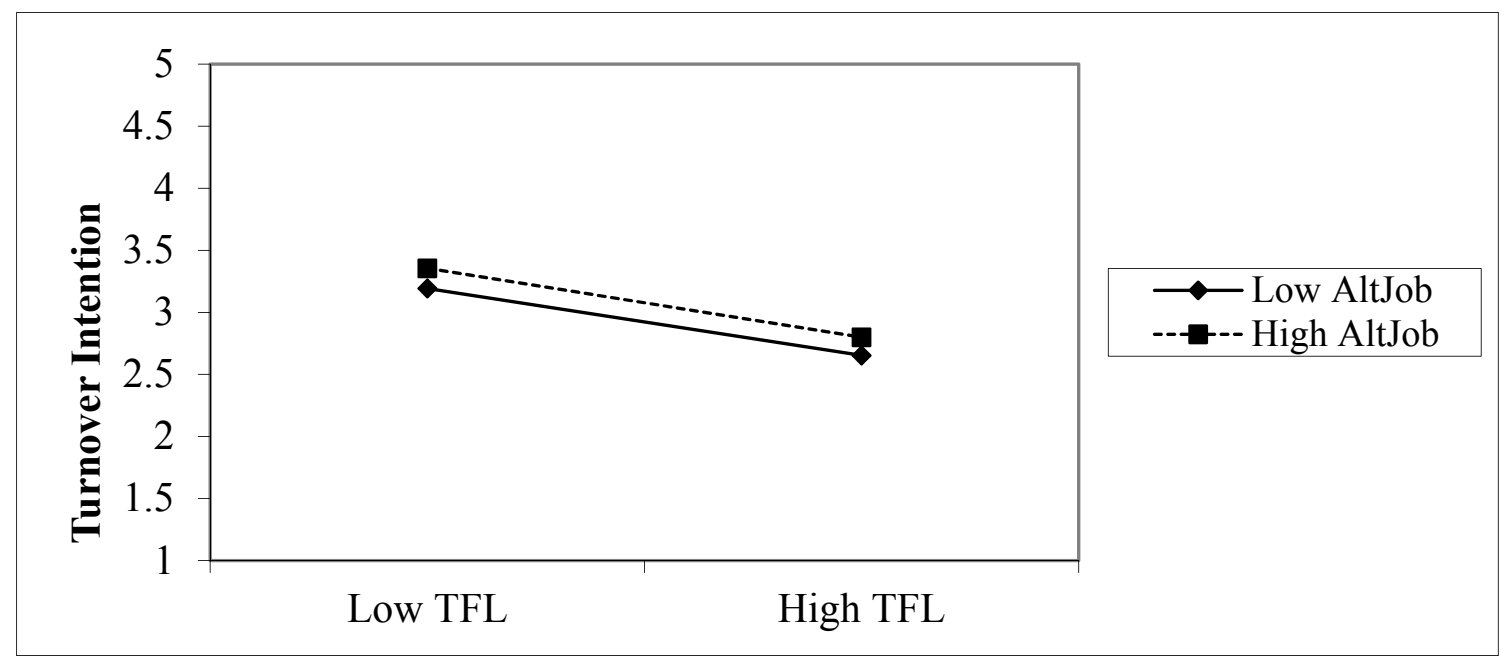

Figure 1. Alternative job opportunity as a moderator of transformational leadership-turnover intention

Note: TFL indicates transformational leadership, AltJob denotes alternative Job opportunity

\subsection{Discussion of Findings}

Consistent with the formulated hypothesis, results from this study indicated a significant negative influence $(\beta=$ $-.289, p<.01)$ of transformational leadership on employee turnover intention. This finding is consistent with Dupre and Day's (2007) study which found that factors associated with supportive management of employees were negatively related to turnover intention through the mediating effect of job satisfaction. Similarly, Alexandrov et al. (2007) argued that employees' perception of management concern for both employees and customers has a significant influence on turnover intention. This finding also supports to the study of Hamstra et al. (2011) which found, in a quantitative study, on how a fit between leadership styles and followers' regulatory focus will mitigate followers' turnover intention that transformational leadership negatively related to turnover intention for highly promotion-focused followers. Furthermore, Pieterse-Landman (2012) in a non-experimental quantitative study examined the relationship between leadership and employee turnover intention. Using a data from a sample of 185 managers in local JSE-listed manufacturing companies in South Africa, the author found a significant negative relationship between transformational leadership and intention to quit. Consistent with these findings, a study by Hughes et al. (2010) on leadership and followers' quitting intention and job search behaviours reported that followers' perceptions of transformational leadership shared significant inverse relationships with their intention to quit.

Besides, the finding of this study is consistent with several other distinguished studies. For instance, Long et al. (2012) in an exploratory study examined the relationship between leadership styles and employee turnover intention among academic staff in a community college in Malaysia and these authors found that transformational leadership was negatively related to turnover intention. Also, in the study conducted by Gul et al. (2003) to investigate the association between leadership styles, organisational commitment and turnover intention, it was revealed that there was a negative but insignificant relationship between turnover and transformational leadership style.

Again, the study of Wells \& Pearchey (2011) to investigate the relationship between leadership behaviours, satisfaction with the leaders, and voluntary turnover intention on 200 participants from National Collegiate Athletic 
Association Division I softball and volleyball assistant coaches in the USA found a significant negative relationship between transformational leadership style and voluntary turnover intention. The implication of the finding is that the more employees perceive their supervisors or managers to exhibit transformational leadership behaviours, the less likely they are to quit their jobs. Hence, transformational leadership may be considered as an effective tool to mitigating employee turnover. It therefore behooves on management of the Ghanaian banks to reduce the upswing of staff turnover and increase the likelihood of business success by implementing and providing an environment that focuses primarily on transformational leadership behaviours. It is also essential that managers and management in general within the Ghanaian banking industry exhibit transformational leadership behaviours with the view to promoting employee well-being and mitigating turnover intention; a phenomenon that has negative consequences on organisations.

\section{Conclusions and Recommendations}

It is arguably evident that in a contemporary business environment dominated by fierce competition and overwhelming technological changes, employees have become more sensitive and knowledgeable of the work environment. Employees thus demand full attention to plans geared towards their growth and career development and they may resist managerial behaviours which seek to oust them from realizing their personal goals. Furthermore, employees are being more likely to be committed to an organisational course that seeks to satisfy their personal needs. Research on leadership styles and employee turnover intention in a developing country context is critical to private and public organisational success in that it provides enough evidence for management of organisations to manage their human resources as the core to success.

The argument that human resources are that which generates sustained competitive advantage for businesses is evidenced in the considerable amount of money organisations lose when they need to replace one employee. Losing human resources therefore poses serious challenge to all organisations and requires careful examination to understand the factors that antecede this phenomenon, turnover, and the possible ways of mitigating its consequences. In order for management to fully appreciate the turnover phenomenon and effectively mitigate it, it is imperious for management to employ transformational leadership behaviours as an efficient tool to addressing the bedeviling consequences of turnover in the Ghanaian banking industry.

\section{References}

Alexandrov, A., Babakus, E., \& Yavas, U. (2007). The effects of perceived management concern for frontline employees and customers on turnover intention. Journal of Service Research, 9, 356-371. http://dx.doi.org/10.1177/1094670507299378

Ali, N. (2009). Factors affecting overall job satisfaction and turnover intention. Journal of Managerial Sciences, 2(2), 239-252.

Allen, N.J., \& Meyer, J.P. (2000). Construct validation in organisational behaviour research: The case of organisational commitment. In R. D. Goffin, \& E. Helmes (Ed.), Problems and solutions in human assessment (pp. 285-314). Boston: Kluwer Academic Publishers. http://dx.doi.org/10.1007/978-1-4615-4397-8_13

Amediku, S. (2008). An overview of employment and labour cost in the Ghanaian Banking, working paper.

Antonakis, J., Avolio, B.J., \& Sivasubramaniam, N. (2003). Context and leadership: An examination of the nine-factor full-range leadership theory using the Multifactor Leadership Questionnaire. Leadership Quarterly, 14(3), 261-295. http://dx.doi.org/10.1016/S1048-9843(03)00030-4

Arnold, J. (1999). Graduates work experiences as predictors of organisational commitment, intention to leave, and turnover: Which experiences really matter? Applied Psychology: an International Review, 48(2), 211-238. http://dx.doi.org/10.1080/026999499377628

Bass, B.M. (1985). Leadership and performance beyond expectations. New York: Free Press.

Bass, B.M. (1990). From transactional to transformational leadership: learning to share the vision. Organisational Dynamics, 18(3), 19-31. http://dx.doi.org/10.1016/0090-2616(90)90061-S

Bass, B.M., \& Avolio, B.J. (2004). Multifactor leadership questionnaire: Manual and sampler set ( ${ }^{\text {rd }}$ ed.). Palo Alto, CA: Mind Garden Inc.

Bass, B.M., \& Riggio, R.E. (2006). Transformational leadership. Mahwah, New Jersey 07430: Lawrence Erlbaum Associates, Inc.

Brown, R. (1996). Organisational commitment: Clarifying the concept and simplifying the existing construct typology. Journal of Vocational Behaviour, 49, 230-251. http://dx.doi.org/10.1006/jvbe.1996.0042 
Burns, J.M. (1978). Leadership. New York: Harper \& Row.

Bycio, P., Hackett, R.D., \& Allen, J.S. (1995). Further assessment of Bass's (1985) conceptualization of transactional and transformational leadership. Journal of Applied Psychology, 80, 468-478.

Cascio, W.F. (2000). Costing human resources: The financial impact of behavior in organizations $\left(4^{\text {th }}\right.$ ed.). Boston, MA: PWS-Kent Publishing Company.

Chapman, P.G. (1993). The Economics of training ( $1^{\text {st }}$ ed.). Exeter UK, BPCC Whearons Ltd.

Creswell. J.W. (2009). Research design: Qualitative, quantitative, and mixed methods approaches ( $3^{\text {rd }}$ ed.). Sage Publications, Inc. London.

Drummond, C. (2002). Accelerating reinforcement learning by composing solutions of automatically identified subtasks. Journal of Artificial and Intelligence Research, 16, 59-104.

Dupre, K.E., \& Day, A.L. (2007). The effects of supportive management and job quality on the turnover intention and health of military personnel. Human Resource Management, 46, 185-201.

Dwomoh, G., \& Korankye, T. (2012). Labour turnover and its impact on performance of Banks in Ghana. European Journal of Business and Management, 4(7), 2222-2839.

Gill, A.S., Flaschner, A.B., \& Shacha, M. (2006). Mitigating stress and burnout by implementing transformational-leadership. International Journal of Contemporary Hospitality Management, 18(6), 469-481.

Gustafson, C.M. (2002). Staff turnover: Retention. International Journal of Contemporary Hospitality Management, 14(3), 106-110. http://dx.doi.org/10.1108/09596110210424385

Hamstra, M.R.W., Van Yperen, N.W., Wisse, B., \& Sassenberg, K. (2011). Transformational-transactional leadership styles and followers' regulatory focus: Fit reduces followers' turnover intention. Journal of Personnel Psychology, 10(4), 182-186. http://dx.doi.org/10.1027/1866-5888/a000043

Hersey, P., \& Blanchard, K.B. (1993). Management of organization behavior utilizing human resources ( ${ }^{\text {th }}$ ed.). Englewood Cliffs. NJ: Prentice-Hall.

Hinkin, T.R., \& Tracey, J.B. (2000, June). The cost of turnover, putting a price on the learning curve. Cornell Hotel and Restaurant Administration Quarterly, 14-20. http://dx.doi.org/10.1177/001088040004100313

Hofstede, G. (1984). The cultural relativity of the quality of life concept. Academy of Management Revie, 9, 389-398.

House, R.J., Wright, N.S., \& Aditya, R.N. (1997). Cross-cultural research on organizational leadership: A critical analysis and a proposed theory. In P. C. Earley \& M. Erez (Eds.), New perspectives on international industrial/organizational psychology. San Francisco, CA: Jossey-Bass.

Hughes, L.W., Avey, J.B., \& Nixon, D.R. (2010). Relationships between leadership and followers' quitting intention and job search behaviours. Journal of Leadership \& Organisational Studies, 17(4), 351-362.

Hukpati, C.A. (2009). Transformational leadership and teacher job satisfaction: A comparative study of private and public tertiary institutions in Ghana. Thesis.

Jackofsky, E.F., \& Slocum, T.W. (1987). A causal analysis of the impact of job performance on the voluntary turnover process. Journal of Occupational Behaviour, 8(3), 263-270. http://dx.doi.org/10.1002/job.4030080307

Jong, P.J., \& Hartog, D.N. (2007). How leaders influence employees' innovative behaviour. European Journal of Innovation Management, 10(1), 41-64. http://dx.doi.org/10.1108/14601060710720546

Judge, T.A., \& Piccolo, R.F. (2004). Transformational and transactional leadership: a meta-analytic test of their relative validity. Journal of Applied Psychology, 89(5), 755-768. http://dx.doi.org/10.1037/0021-9010.89.5.755

Kahumuza, J., \& Schlechter, A.F. (2008). Examining the direct and some mediated relationships between perceived support and intention to quit. Journal of the South African Institute for Management Scientists, 17(3), 2-19.

Kark, R., Shamir, B., \& Chen, G. (2003). The two faces of transformational leadership: empowerment and dependency. Journal of Applied Psychology, 88(2), 246-255. http://dx.doi.org/10.1037/0021-9010.88.2.246

Kedsuda, L., \& Ogunlana, S.O. (2008). Performance and leadership outcome correlates of Leadership Styles and subordinate commitment. Engineering, Construction and Architectural Management, 15(2), 164-184.

Khatri, N., Budhwar, P., \& Fern, C.T. (1999). Employee turnover: bad attitude or poor management? (Electronic version). Retrieved September 12, 2013, from ww3.ntu.edu.sg/nbs/sabre/working _papers/13-99.pdf 
Klein, H.J., Molloy, J., \& Cooper, J.T. (2009). Conceptual foundations: Construct definitions and theoretical representations of workplace commitment. In H. Klein, T. Becker, \& J. Meyer (Eds.), Commitment in organizations: Accumulated wisdom and new directions. New York, NY: Routledge.

Komives, S.R., \& Wagner, W. (Eds.). (2009). Leadership for a better world: Understanding the social change model of leadership development ( $2^{\text {nd }}$ ed.). San Francisco, CA: Jossey-Bass.

Kumar, R., Ramendran, C., \& Yacob, P. (2012). A study on turnover intention in fast food industry: Employees' fit to the organizational culture and the important of their commitment. International Journal of Academic Research in Business and Social Sciences, 2(5).

Larry, W., Hughes, J., Avey, B., \& Don, R.N. (2010). Relationships between leadership and followers' quitting intentions and job search behaviors. Journal of Leadership \& Organizational Studies, 17(4), 351-362.

Leithwood, K. (1994). Leadership for school restructuring. Educational Administration Quarterly, 30(4), 498-518.

Lewin, K., Lippit, R., \& White, R.K. (1939). Patterns of aggressive behavior in experimentally created social climates. Journal of Social Psychology, 10, 271-301. http://dx.doi.org/10.1080/00224545.1939.9713366

Long, C.S., Thean, L.Y., Ismail, W.K., \& Jusoh, A. (2012). Leadership styles and employees' turnover intention: Exploratory study of academic staff in Malaysian college. World Applied Sciences Journal, 19(4), 575-581.

Loquercio, D., Harmmersley, M., \& Emmens, B. (2006). Understanding and addressing staffturnover in humanitarian agencies. Oversees Development Institute [ODI]: The Humanitarian Practice Network.

Martin, R., \& Epitropaki, O. (2001). Role of organizational identification on implicit leadership theories (ILTS), transformational leadership and work attitudes. Group Process Intergroup Relations, 4, 247-262.

Miller, R.L., \& Brewer, J.D. (Eds.) (2003). A-Z of social research. London: Sage Publications.

Mobley, W.H., Griffeth, R.W., Hand, H.H., \& Meglino, B.M. (1979). Review and concept analysis of the employee turnover process. Psychological Bulletin, 14, 224-247.

Moss, S.A., \& Ritossa, D.A. (2007). The impact of goal orientation on the association between leadership style and follower performance, creativity and work attitudes. Leadership \& Organization Development Journal, 3(4), 433-456. http://dx.doi.org/10.1177/1742715007082966

Mueller, C.W., \& Price, J.L. (1990). Economic, psychological, and sociological determinants of voluntary turnover. The Journal of Behavioral Economics, 19, 321-335. http://dx.doi.org/10.1016/0090-5720(90)90034-5

Najm, M.A. (2010). Studying the influence of the transformational and transactional leadership behaviours on the success of the project and on employees' turnover intention. A master's thesis, University of Kuwait, Kuwait.

Onyishi, I.E., Ucho, A., \& Mkavga, T. (2012). Job satisfaction, gender, tenure, and turnover intention among civil servants in Benue State. Interdisciplinary Journal of Contemporary Research in Business, 3(11), 213-226.

Pieterse-Landman, E. (2012). The relationship between transformational leadership, employee engagement, job characteristics and intention to quit. A master's thesis, Stellenbosch University, South Africa.

Powell, D., \& Meyer, J. (2004). Side-bet theory and the three-component model of organisational commitment. Journal of Vocational Behaviour, 65, 157-177. http://dx.doi.org/10.1016/S0001-8791(03)00050-2

Price, J. (1997). Handbook of organisational measurement. International journal of manpower, 18, 303-558.

Schermerhorn, J.R. (1999). Management $\left(6^{\text {th }}\right.$ ed.). New York: John Wiley \& Sons, Inc.

Shamir, B., House, R.J., \& Arthur, M.B. (1993). The motivational effects of charismatic leadership: A self-concept based theory. Organization Science, 4, 577-594. http://dx.doi.org/10.1287/orsc.4.4.577

Staw, B. (1980). The consequences of turnover. Journal of Occupational Behaviour, 1(4), 253-273.

Tziner, A., \& Birati, A. (1996). Assessing employee turnover costs: A revised approach. Human Resource Management Review, 6, 133-122. http://dx.doi.org/10.1016/S1053-4822(96)90015-7

Vance, R.J. (2006). Employee engagement and commitment: A guide to understanding, measuring, and increasing engagement in your organisation. Alexandria, VA: The SHRM Foundation.

Wells, J.E., \& Pearchey, J.W. (2011). Turnover intentions: Do leadership behaviours and satisfaction with leader matter? Team Performance management, 17(1), 23-40. http://dx.doi.org/10.1108/13527591111114693 